Article

\title{
Predicted Studies of Branched and Cross-Linked Polyurethanes Based on Polyhydroxybutyrate with Polycaprolactone Triol in Soft Segments
}

\author{
Joanna Brzeska ${ }^{1, *(1)}$, Agnieszka Tercjak ${ }^{2}(0)$, Wanda Sikorska ${ }^{3, *}$, Marek Kowalczuk ${ }^{3}$ and $^{-}$ \\ Maria Rutkowska ${ }^{1}$ \\ 1 Department of Commodity Industrial Science and Chemistry, Gdynia Maritime University, 83 Morska Street, \\ 81-225 Gdynia, Poland; m.rutkowska@wpit.umg.edu.pl \\ 2 Department of Chemical and Environmental Engineering, Group 'Materials+Technologies' (GMT), \\ University of the Basque Country (UPV/EHU), Plaza Europa 1, 20018 Donostia-San Sebastián, Spain; \\ agnieszka.tercjaks@ehu.eus \\ 3 Centre of Polymer and Carbon Materials, Polish Academy of Sciences, 34 M. Curie-Sklodowska Street, \\ 41-819 Zabrze, Poland; marek.kowalczuk@cmpw-pan.edu.pl \\ * Correspondence: j.brzeska@wpit.umg.edu.pl (J.B.); wsikorska@cmpw-pan.edu.pl (W.S.)
}

Received: 7 April 2020; Accepted: 3 May 2020; Published: 7 May 2020

\begin{abstract}
The number of cross-links in the non-linear polyurethane structure is the basic factor affecting its properties. Selected properties of aliphatic polyurethanes with soft segments made of different amounts of polycaprolactonetriol, polycaprolactonediol and synthetic, telechelic poly([R,S]-3hydroxybutyrate) were determined. On the basis of changes in polyurethane properties, the correlation between these properties and the construction of soft segments was found. The structure of polyurethanes, their morphology, hydrophilicity, thermal and mechanical properties were examined. These properties were changed linearly up to $15 \%$ content of polycaprolactonetriol in soft segments. A further increase in the amount of triol causes that these properties are mainly determined by the high number of cross-links.
\end{abstract}

Keywords: polyurethane structure; branched and cross-linked polyurethanes; synthetic polyhydroxybutyrate; polycaprolactone triol; chemical structure; water affinity; thermal and mechanical properties; surface topography

\section{Introduction}

Polyurethanes are versatile materials, and due to their easy modification, can be used in many industries. Considering the theoretical structure of branched and cross-linked polyurethanes, their properties are mainly affected: (i) By the characteristics of substrates used for their building (such as hydrophilicity, crystallinity, degradability, etc.); (ii) by the molecular weight and the degree of polymerization; (iii) by the degree of branching/cross-linking and length of chains between branching/cross-linking nodes; (iv) and by the number of short and long side chains. These parameters affect the ability to form hydrogen bonds, and this influences almost all properties of the material: Its crystallinity, mechanical strength, wettability, sorption properties, degradability and many others. However, the above-mentioned parameters work synergistically and properties of the obtained materials are the effect of the influence of all of them.

The fundamental way to obtain polyurethane with the desired properties is to select the appropriate substrates for its synthesis. A method to obtain environmentally friendly or compatible with a living organism polyurethane can be to use a natural compound for its synthesis, e.g., polyhydroxybutyrate (PHB). PHB is the most popular compound among all polyhydroxyalkanoates due its biocompatibility, 
biodegradability and natural origin [1-3]. However, despite the undoubted benefits of using PHB, its high crystallinity, brittleness, high production costs, poor mechanical properties and thermal instability cause that its use is limited. A few methods are employed to improve PHB characteristics, such as: Drawing and thermal treatment, blending with other biopolymers and synthetic polymers, forming composites with natural fibers and inorganic fillers and others [4]. However, it is beneficial to replace natural PHB with its synthetic analogue, which is also biocompatible and biodegradable, but possess R,S configuration on $\beta$-carbon. Synthetic PHB is synthetized via polymerization of $\beta$-butyrolactone (4-methyl-2-oxetanone), using coordination, cationic or anionic ring-opening polymerization, and depending on the kind of monomer and polymerization mechanism can be obtained in R, S or R,S configuration [5]. If PHB is obtained as poly([R,S]-3-hydroxybutyrate) (R,S-PHB) its character is almost completely amorphous. Through the appropriate method of modification it can be formed into telechelic polyol with hydroxyl groups at the ends of its chains [6], and can be used to build soft segments of polyurethanes. The presence of amorphous R,S-PHB with a very short side chain $\left(\mathrm{CH}_{3}\right)$ in the polyurethane structure should influence its properties, such as a change of crystallinity, which facilitates water migration into the polyurethane network, and others.

Due to the wide spectrum of potential applications of polymer biomaterials, e.g., in medicine, for the production of compostable polymer packaging (such as cosmetics or food), as well as in agrochemical preparations, forensic engineering on advanced polymeric materials (FEAPM) can provide basic knowledge and valuable information to prevent future problems. FEAPM deals with the knowledge and evaluation of relationships between the structure, properties and behavior of polymer materials before, during and after practical applications. This approach also allows predicting the properties of new polyurethanes depending on their structure and composition of the soft segments. In paper the correlation between the quantity of polycaprolactone triol in soft segments and properties of branched and cross-linked polyurethanes based on poly([R,S]-3-hydroxybutyrate) diol were presented. The paper is a continuation of previous research on the impact of linear and branched polyurethane structures on their properties [7]. Here, three series of polyurethanes, different with regard to their amount of polycaprolactone triol and poly([R,S]-3-hydroxybutyrate) diol were synthetized and characterized.

\section{Experimental}

\subsection{Materials}

Poly([R,S]-3-hydroxybutyrate) diol was synthetized via polymerization of $\beta$-butyrolactone (Aldrich, St. Luis, MO, USA), using anionic ring-opening polymerization, initiated by 3-hydroxybutyric acid sodium salt (Aldrich, St. Luis, MO, USA)/18-crown-6 complex (Fluka, Germany), at room temperature and terminated with 2-iodoethanol or 2-bromoethanol (Aldrich, St. Luis, MO, USA) [6]. Oligomerols of R,S-PHB $\left(\mathrm{M}_{\mathrm{n}} 2100\right), \mathrm{PCL}_{\text {triol }}\left(M_{\mathrm{n}} 900\right.$, Aldrich, St. Luis, MO, USA) and PCL $\mathrm{Liol}\left(M_{\mathrm{n}}\right.$ 1900 , Aldrich, St. Luis, MO, USA) were dried by heating at $70^{\circ} \mathrm{C}$ under reduced pressure $(1.4 \mathrm{hPa})$. 4,4'-methylene dicyclohexyl diisocyanate $\left(\mathrm{H}_{12} \mathrm{MDI}\right.$ ) (Aldrich, St. Luis, $\left.\mathrm{MO}, \mathrm{USA}\right)$ was vacuum distilled; 1,4-butanediol (1,4-BD) (Aldrich, Steinheim, Germany) was distilled azeotropically with benzene; $\mathrm{N}, \mathrm{N}$-dimethylformamide (DMF) (Chempur, Gliwice, Poland) was dehydrated over diphosphorous pentoxide $\left(\mathrm{P}_{2} \mathrm{O}_{5}\right)$ and distilled under low pressure. Catalyst tin(II) octanoate (OSn) (Alfa Aestar, Karlsruhe, Germany) was used as received.

\subsection{Methods}

\subsubsection{Chemical Structure}

Attenuated Total Reflectance Fourier Transform Infrared Spectroscopy (ATR FTIR) was used to determine the characteristic groups of polyurethanes. FTIR spectra were recorded with an attenuated total reflection (ATR, Smart Orbit Accessory, Thermo Scientific, Madison, WI, USA) mode on a NICOLET 
380 FTIR spectrometer (Thermo Scientific, Madison, WI, USA) with a diamond cell. Resolution of $4 \mathrm{~cm}^{-1}$ and the scanning range from 400 to $4000 \mathrm{~cm}^{-1}$ were applied, and 32 scans were taken for each measurement.

\subsubsection{Surface Topography}

Atomic Force Microscopy (AFM) images were obtained with a Nanoscope V scanning probe microscope (Multimode 8, Digital Instruments, Bruker, Billerica, MA, USA) under ambient conditions. Tapping Mode (TM) was employed in air using an integrated tip/cantilever (125 $\mathrm{m}$ in length with ca. $300 \mathrm{kHz}$ resonant frequency). Typical scan rates during recording were 0.7 to 1 line/s using a scan head with the maximum range of $15 \mu \mathrm{m} \times 15 \mu \mathrm{m}$. Some samples were cut using an ultramicrotome Leica Ultracut $R$ with a diamond blade to obtain a sample cross section.

Optical Microscopy (OM) micrographs were taken using a Nikon Eclipse E600W microscope (Mettler FP 82 HT, Melvile, NY, USA). These micrographs were collected with the software analySIS docu FIVE.

\subsubsection{Thermal Properties}

Differential Scanning Calorimetry (DSC) measurements were performed using a Mettler Toledo DSC3+ (Mettler Toledo, Columbus, OH, USA). All the investigated samples were first heated from -80 to $190{ }^{\circ} \mathrm{C}$ at $10^{\circ} \mathrm{C} \cdot \mathrm{min}^{-1}$, then cooled from $190-80{ }^{\circ} \mathrm{C}$ at $10^{\circ} \mathrm{C} \cdot \mathrm{min}^{-1}$ and finally, they were melted by heating up to $190^{\circ} \mathrm{C}$ at $10^{\circ} \mathrm{C} \cdot \mathrm{min}^{-1}$. All the experiments were conducted under a nitrogen flow of $10 \mathrm{~mL} / \mathrm{min}$ using 5 to $10 \mathrm{mg}$ samples in aluminum pans.

Thermogravimetric Analysis (TGA) was performed with TGA/SDTA-851e equipment (Mettler Toledo, Columbus, $\mathrm{OH}, \mathrm{USA}$ ) under air atmosphere at the heating rate of $10^{\circ} \mathrm{C} \cdot \mathrm{min}^{-1}$ from room temperature to $800^{\circ} \mathrm{C}$.

\subsubsection{Water Contact Angle Measurements}

Static water contact angle measurements were carried out using the Data Physics OCA 20 contact angle system (SEO Phoenix 300, Suwon, Korea) at ambient temperature. A $5 \mathrm{~mL}$ distilled water drop was used for each measurement and a photo of the drop was taken after 0, 1 and $3 \mathrm{~min}$ from immersing the drop on the sample surface. At least five measurements were made for each different system.

\subsubsection{Density}

The density of polymer samples was determined according to the ISO 1183 standard and using analytical balance equipped with a density determination kit (Radwag, AS 160.X2, Radom, Poland).

Oil sorption and water sorption were measured according to ASTM D2842 (equivalent to ISO 2896) [8]. Samples were dried for $3 \mathrm{~h}$ at $40^{\circ} \mathrm{C}$ and then weighed. The samples were immersed in oil or distilled water to the depth of $1 \mathrm{~cm}$. PURs were immersed in sunflower oil at $37^{\circ} \mathrm{C}$ for $24 \mathrm{~h}$ and next they were weighed after wiping off the oil with filter paper.

For water sorption estimation, the investigated polymers were immersed in deionized water for 21 days at $37^{\circ} \mathrm{C}$. Periodically, these specimens were removed from the solvent and weighed after removing an excess of the solvent from the sample using filter paper.

Sorption was calculated (using the gravimetric method) from the weight after incubation $\left(w_{\mathrm{i}}\right)$ and the initial weight $\left(w_{0}\right)$ by:

$$
\text { Sorption } \%=\left(w_{\mathrm{i}}-w_{0}\right) / w_{0} \times 100 \% .
$$

The results were the average of three measurements. 


\subsubsection{Mechanical Properties}

Test Machine MultiTest-1xt (Mecmesin, Slinfold, West Sussex, UK) was used to estimate tensile strength $\left(\sigma_{\max }\right)$ of the obtained samples. The number of replicates for this test was five. Hardness of the samples was determined by the Shore A method, using HAD 100-1 apparatus (Sauter).

\section{Results and Discussion}

Polyurethanes (PURs) were obtained through the prepolymer method detailed in our previous work $[7,9]$. The diagram of PURs synthesis is presented in Figure 1.

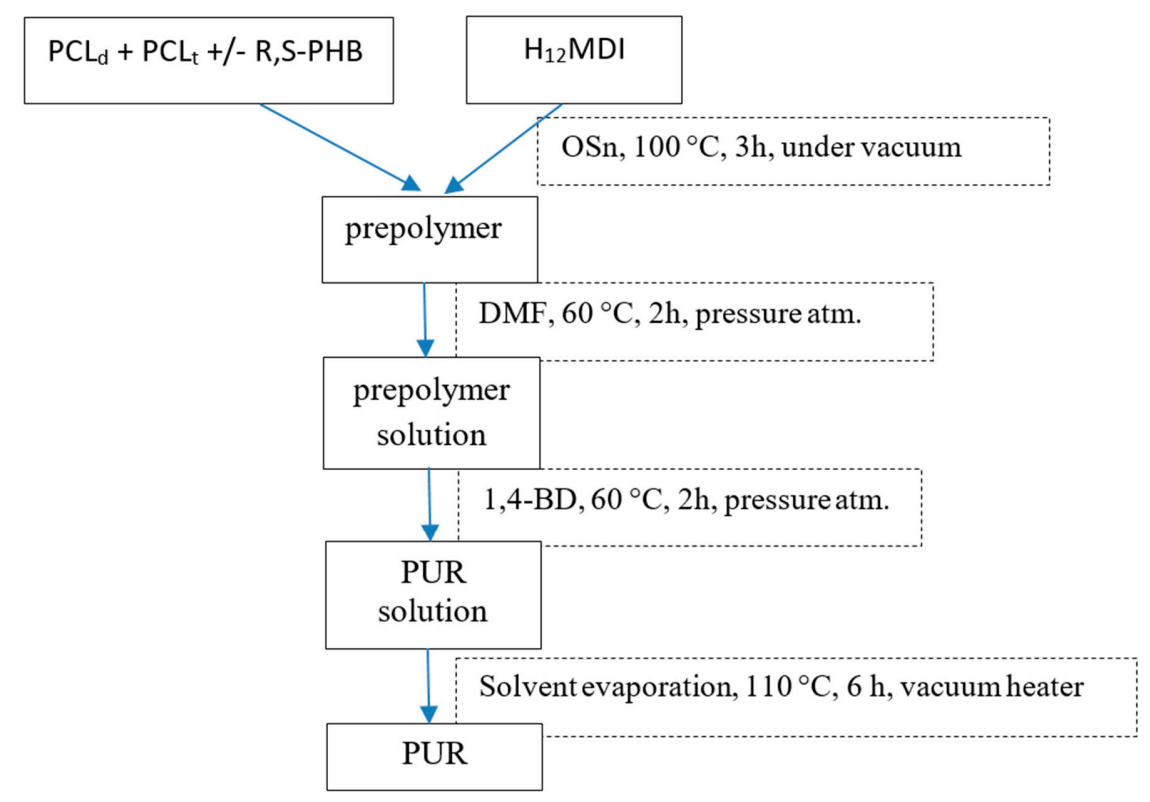

Figure 1. Scheme of PURs synthesis.

Three series of polyurethanes, with different amount of $\mathrm{PCL}_{\mathrm{t}}$, were obtained. Polyurethanes in each series differed in the construction of soft segments. Hard segments were synthetized with $\mathrm{H}_{12} \mathrm{MDI}$ and 1,4-BD in each case. The molar ratio of $\mathrm{NCO}: \mathrm{OH}$ in prepolymer was always 2:1, whereas the total ratio in PUR was 1:1.

The chemical composition of synthetized PURs is presented in Table 1. PUR series are named according to percentage of oligomerol in soft segments ( $w t \%$ ) of the used R,S-PHB/PCL $\mathrm{P}_{t}$ system.

Table 1. Chemical composition of PURs.

\begin{tabular}{|c|c|c|c|c|c|c|}
\hline \multirow{2}{*}{$\begin{array}{l}\text { PUR } \\
(\text { PHB/PCL })\end{array}$} & \multicolumn{3}{|c|}{ Percentage of Oligomerol in Soft Segments (wt \%) } & \multirow{2}{*}{$\begin{array}{c}\mathbf{M}_{\mathrm{c}} \\
(\mathrm{g} / \mathrm{mol})\end{array}$} & \multirow{2}{*}{$\begin{array}{c}\text { Side } \mathrm{CH}_{3} \\
\text { Content }(\%)\end{array}$} & \multirow{2}{*}{$\begin{array}{c}\text { Side } \mathrm{C}_{2} \mathrm{H}_{5} \\
\text { Content }(\%)\end{array}$} \\
\hline & R,S-PHB & $\mathrm{PCL}_{\mathrm{t}}$ & $\mathrm{PCL}_{\mathrm{d}}$ & & & \\
\hline PUR 0/5 & 0 & 5 & 95 & $24,228.1$ & 0 & 0.6 \\
\hline PUR $10 / 5$ & 10 & 5 & 85 & $24,464.5$ & 1.1 & 0.6 \\
\hline PUR 20/5 & 20 & 5 & 75 & $24,401.6$ & 2.2 & 0.6 \\
\hline PUR 30/5 & 30 & 5 & 65 & $24,095.2$ & 3.3 & 0.6 \\
\hline PUR 0/15 & 0 & 15 & 85 & 8508.9 & 0 & 1.6 \\
\hline PUR 10/15 & 10 & 15 & 75 & 8503.8 & 1.1 & 1.6 \\
\hline PUR 20/15 & 20 & 15 & 65 & 8068.8 & 2.2 & 1.6 \\
\hline PUR 15/20 & 15 & 20 & 65 & 6048.6 & 1.6 & 2.2 \\
\hline PUR 30/20 & 30 & 20 & 50 & 6041.9 & 3.3 & 2.2 \\
\hline PUR 45/20 & 45 & 20 & 35 & 6032.6 & 5.0 & 2.2 \\
\hline
\end{tabular}


Percentage content of side $\mathrm{CH}_{3}$ (from R,S-PHB) and side $\mathrm{C}_{2} \mathrm{H}_{5}$ (from $\mathrm{PCL}_{\mathrm{t}}$ ) was estimated according to [10] and is given in Table 1 . As $\mathrm{C}_{2} \mathrm{H}_{5}$ is attached to the carbon at the branching point of $\mathrm{PCL}_{\mathrm{t}}$, an increase in its amount in the PUR structure indicates an increase in the degree of branching. Cross-linking and branching density of the polymer network is also expressed through the calculated molecular weight of chains between the branching/cross-linking point $\left(M_{\mathrm{c}}\right)$ [11], and is calculated according to [10].

Considering starting substrates used for the synthesis of polyurethanes, it can be assumed that their properties will be influenced by the type and the amount of polyols used, and this will also affect the structure of the polymer: Chain length between branching/cross-linking nodes, and the number of short methyl and ethyl chains, which are a steric hindrance [10].

An increase in the amount of $\mathrm{PCL}_{t}$ in soft segments decreases the chain length between branch nodes, i.e., an increase in $\mathrm{M}_{\mathrm{c}}$. At the same time the number of ethyl side groups increases. Whereas, when the amount of R,S-PHB increases, the number of side methyl groups increases simultaneously.

The synthetized polyurethanes were almost transparent, and those based on R,S-PHB obtained from iodoethanole were slightly yellow (Table 2). Their density was about $1.1 \mathrm{~g} / \mathrm{cm}^{-3}$, independently of the amount of the added triol. Polyurethanes, obtained with $5 \mathrm{wt} \%$ of $P C L_{t}$, were soluble in DMF, which indicated that they were branched; whereas PURs based on the higher amount of $\mathrm{PCL}_{t}$ swelled in DMF, due to the formation of the cross-linked structure. However, it did not affect the oil sorption of PURs, which stays at the same level for all samples studied.

Table 2. Characteristic of polyurethanes.

\begin{tabular}{|c|c|c|c|c|}
\hline PUR (PHB/PCL $)$ & $\begin{array}{l}\text { Density } \\
{\left[\mathrm{g} / \mathrm{cm}^{3}\right]}\end{array}$ & Oil Sorption [\%] & Transparency & $\begin{array}{c}\text { Solubility/Swelling } \\
\text { in DMF }\end{array}$ \\
\hline PUR 0/5 & 1.13 & 0.5 & \multirow{3}{*}{ TR INST'F EINCY } & \multirow{4}{*}{ soluble } \\
\hline PUR $10 / 5$ & 1.14 & 0.6 & & \\
\hline PUR 20/5 & 1.10 & 0.8 & & \\
\hline PUR 30/5 & 1.13 & 0.8 & PUR 0/5 PUR10/5 PUR20/5 PUR30/5 & \\
\hline PUR 0/15 & 1.10 & 0.7 & \multirow{3}{*}{ 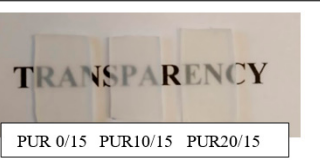 } & \multirow{3}{*}{ swelled } \\
\hline PUR 10/15 & 1.13 & 0.8 & & \\
\hline PUR 20/15 & 1.10 & 0.6 & & \\
\hline PUR 15/20 & 1.13 & 0.6 & \multirow[b]{2}{*}{ TRANSPARENCY } & \multirow{3}{*}{ swelled } \\
\hline PUR 30/20 & 1.12 & 0.6 & & \\
\hline PUR 45/20 & 1.13 & 0.8 & PUR15/20 PUR30/20 PUR45/20 & \\
\hline
\end{tabular}

The chemical structure of the synthesized PURs was confirmed via FTIR spectroscopy (Figure S1, Supplementary Materials). The characteristic absorption bands which appeared in the FTIR spectra and proved the urethane linkage formation were: A broad absorption band centered at about $3350 \mathrm{~cm}^{-1}$, which corresponded to $-\mathrm{NH}$ groups ( $-\mathrm{NH}$ stretching vibrations), the peak corresponding to $\mathrm{C}=\mathrm{O}$ stretching vibrations observed around $1720 \mathrm{~cm}^{-1}$, and peaks of an amide II band and an amide III band around 1520 and $1240 \mathrm{~cm}^{-1}$, respectively (Table S1, Supplementary Materials). On FTIR spectra of PURs, the band corresponding to $-\mathrm{NCO}\left(2270 \mathrm{~cm}^{-1}\right)$ disappeared. Generally, individual spectra of the all polyurethanes were very similar (Figure S1, Supplementary Materials).

The main differences were observed in the multiple band in the range $1040 \mathrm{~cm}^{-1}$ to $1245 \mathrm{~cm}^{-1}$ assigned to stretching $\mathrm{C}-\mathrm{O}$ bonds in soft segments [12] (Figure 2). Shifting these peaks in this range, after adding or increasing the amount of R,S-PHB, indicated that this polyol was successfully incorporated into the PURs structure (Figure S2, Supplementary Materials).

Introducing an amorphous R,S-PHB with a lower distance between carbonyl groups in the chain than PCL into soft segments increased possible interaction between urethane and carbonyl groups. 
Such an increase in hydrogen bond formation after introducing a substrate with a larger number of hydrogen bonding sites was already observed [13]. In consequence, more hydrogen bonded $-\mathrm{N}-\mathrm{H}$ groups were formed and the band of their stretching vibration (around $3350 \mathrm{~cm}^{-1}$ ) shifted to a lower wavenumber (Table S1, Supplementary Materials).

The intensity of the C-H stretching vibration around $2920 \mathrm{~cm}^{-1}$ (Figure S1, Supplementary Materials) was used as the standard against which the intensity of the urethane carbonyl bands at $1720 \mathrm{~cm}^{-1}$ was compared. As the length of the repeating mer in R,S-PHB was shorter than in PCL, the frequency of arising urethane groups and the amount of carbonyl ester groups were greater in polyurethane structure after R,S-PHB using for the synthesis of soft segments. This caused the intensity of the carbonyl of PUR $x / 5$ to increase with increasing amounts of R,S-PHB. This indicated the presence of R,S-PHB on the polyurethane surface. However, after using a higher amount of $\mathrm{PCL}_{t}$ for PUR x/15 and PUR $x / 20$ building, the changes in peak intensity were not so straightforward. The reason was probably the inhibition of chain mobility after increasing the number of crosslinks.

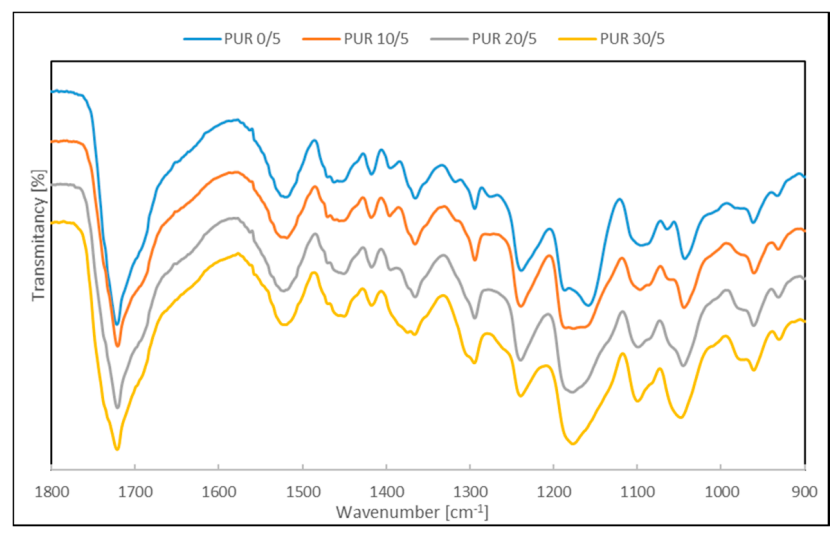

(a)

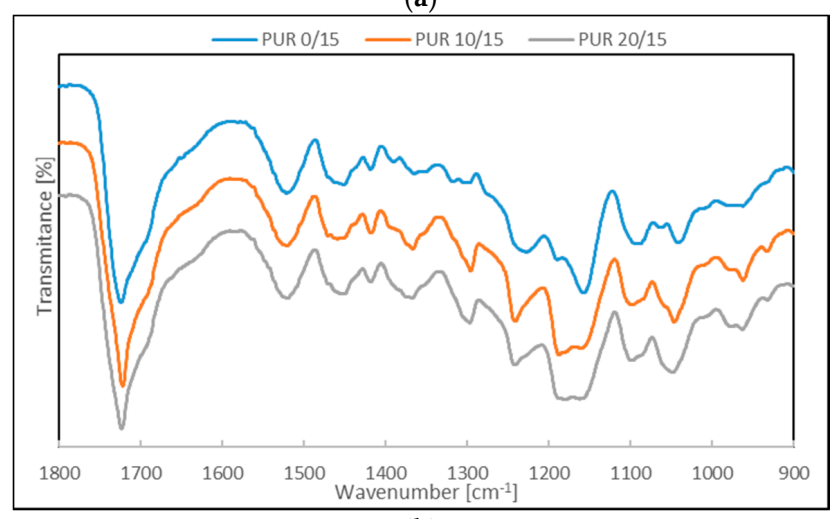

(b)

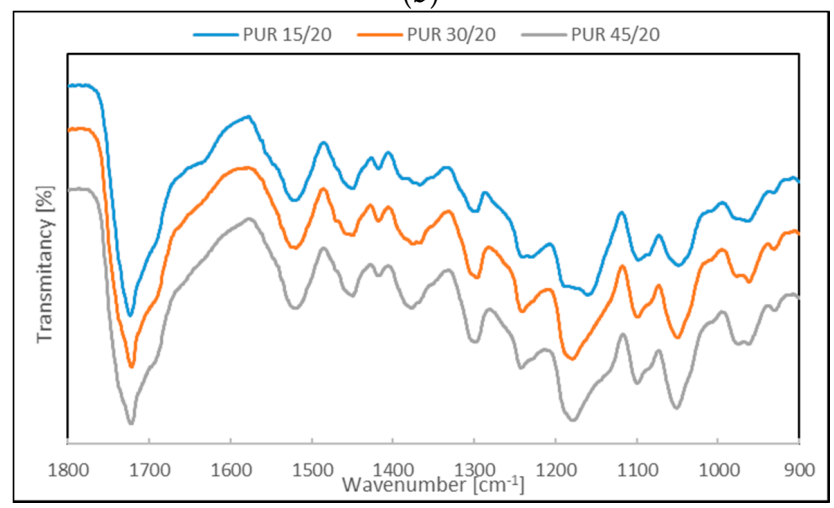

(c)

Figure 2. ATR-FTIR spectra in the range $900 \mathrm{~cm}^{-1}$ to $1800 \mathrm{~cm}^{-1}$ of (a) PUR $x / 5$, (b) PUR $x / 15$ and (c) PUR $x / 20$. 
Crystallinity of the synthetized PURs was low. Only PURs based on $5 \mathrm{wt} \%$ of PCL $\mathrm{L}_{\mathrm{t}}$ in soft segments had the pronounced melting peak with significant melting enthalpy (Figure 3). Increasing R,S-PHB in the soft segments structure of PURs with the higher amount of $\mathrm{PCL}_{t}$ increased discreetly melting enthalpy. Despite the amorphous nature of R,S-PHB, its presence in the polymer network facilitated PCL chains moving and forming into crystalline forms. After the ordering of PCL chains, they were stabilized by hydrogen bonds formed due to R,S-PHB presence. Next, these ordered chains were formed into crystalline forms, which was the reason the melting enthalpy increased for PURs with intermate quantities of R,S-PHB present. However, if the amount of R,S-PHB was even greater, its amorphous nature caused the soft segment to become more amorphous. It could be seen that the $T_{\mathrm{m}}$ also slightly increased (Table 3).

Glass transition temperature of soft segments was significantly higher after increasing of R,S-PHB in the PURs structure (Figure 3). The biggest changes were observed for PURs with the highest number of branching points. As glass temperature of oligomer R,S-PHB was $-5.5{ }^{\circ} \mathrm{C}$, its blending with PCL chains increased $T_{\mathrm{g}}$ of soft segments. Presence of the one $T_{\mathrm{g}}$ on DSC thermograms indicated on miscibility of these two oligomerols and increasing the R,S-PHB quantity increased the glass transition temperature.

Since the DSC thermograms from the first heating cycle show all changes occurring in polymer structure during sample formation and subsequent storage, it was assumed that lower $T_{\mathrm{g}}$ PUR x/15 compared to PUR $x / 5$ might result from differences in conditions (e.g., conditioning temperature). However, the results from the second heating cycle clearly showed that the addition of more PCL caused cross-linking of the chains and thus their stiffening, which increased the $T_{\mathrm{g}}{ }^{\mathrm{II}}$ temperature.

The DSC investigation was conducted about 2 months after the synthesis of PURs. During this time, polyurethane chains slowly reorganized and ordered, resulting in the formation of crystalline forms. Therefore, after cooling a PURs sample at the rate of $10^{\circ} \mathrm{C} \cdot \mathrm{min}^{-1}$, it was found out that no crystalline forms were formed in the polymer network. On thermograms of the second heating cycle, only glass transition of the soft segments was observed. Generally, the values of $T_{\mathrm{g}}$ from the second heating scan were lower than the ones obtained from the first heating. Only in the case of PUR 0/15 and PUR 20/15, whose melting enthalpy of soft segments was less than $1 \mathrm{~J} / \mathrm{g}, T_{\mathrm{g}}$ from the second heating was higher. It was concluded that the presence of crystalline forms hindered mobility of chains, which consequently moved $T_{\mathrm{g}}$ to higher temperatures (Table 3 ).

The analysis of the results of the second heating (after eliminating the thermal history of a sample) confirmed compliance with the results presented in [11], which indicated that an increase in $M_{\mathrm{c}}$ resulted in an increment of $T_{\mathrm{g}}$. PURs with the small amount of $\mathrm{PCL}_{\mathrm{t}}$ and $\mathrm{M}_{\mathrm{c}}$ about $24,000 \mathrm{~g} \cdot \mathrm{mol}^{-1}$ had lower $T_{\mathrm{g}}$ II than PURs with higher branching points. Nevertheless, it was concluded that side chains $\mathrm{CH}_{3}$ and $\mathrm{C}_{2} \mathrm{H}_{5}$ were too short to have a plasticizing effect, as it was stated in [11] in the case of side chains in triolein used for PUR synthesise.

Thermal decomposition of PUR was measured by TG and DTG (Figure 4). In the case of PURs without R,S-PHB a one-step process of thermal degradation was observed. Temperature of the maximum degradation of PUR $0 / 5$ and PUR $0 / 15$ was $356{ }^{\circ} \mathrm{C}$, and $362{ }^{\circ} \mathrm{C}$, respectively (Table S3, Supplementary Materials). The initial degradation temperature was higher for PUR 0/15 with the increased number of cross-links, which is in agreement with the literature data $[14,15]$. Increasing the amount of $\mathrm{PCL}_{\mathrm{t}}$ in the structure of soft polyurethane segments, without R,S-PHB clearly increasing the thermal stability of the sample, indicated an increase in cross-linking. However, the addition of R,S-PHB disrupted cross-linking processes. The lower $T_{\mathrm{i}}$ and $T_{5}$ values of polyurethanes with a higher amount of $\mathrm{PCL}_{t}$ compared to PUR $x / 5$ indicated that the polyurethane network had chains with low molecular weights that underwent thermal degradation faster. In addition, the crosslinked networks of these polyurethanes may contain the residual particles of solvent, which further affect the weight reduction during the TG analysis. Derivative TG curves clearly indicated that PURs with R,S-PHB degraded in three stages. The presence of secondary $\mathrm{OH}$ groups in the R,S-PHB structure caused this polyol to be less reactive than $\mathrm{PCL}_{d}$ and $\mathrm{PCL}_{t}$ in reaction with the isocyanate group [16]. The reactivity 
of the secondary group is assumed to be only $30 \%$ of that of primary alcohols [17]. In consequence distribution of molecular weight was therefore probably high. The resulting shorter chains probably degraded at a lower temperature than chain with the high molecular weight and the initial temperature $\left(T_{\mathrm{i}}\right)$ of thermal degradation of PURs with R,S-PHB was lower (Table 3). Such a decrease of degradation temperature with the molecular weight decreasing was observed for poly(dimethylsiloxane) [18] and poly(methyl methacrylate) [19]. Knowing that degradation of PUR starts from a breakage of urethane bonds in hard segments [20], there was a higher intensity of the first peak of the synthetized polyurethanes with R,S-PHB, as the presence of R,S-PHB caused formation of more urethane groups, and temperatures of the initial decomposition and reduction of $5 \%$ and $10 \%$ samples mass were found to be the lowest. Polyurethanes based on high amount of R,S-PHB (PUR 30/5, PUR 30/20 and PUR 45/20) underwent the fastest thermal degradation ( $T_{\mathrm{i}}$ was the lowest), despite the high number of cross-linking nodes (in case of PUR 30/20 and PUR 45/20). The number of side $\left(\mathrm{CH}_{3}\right.$ and $\left.\mathrm{C}_{2} \mathrm{H}_{5}\right)$ chains in PUR 45/20 structure was the highest (Table 1). Their presence caused the macrochains to move away from one another, and as a consequence, the interaction between them was reduced, so the thermal stability was also low.

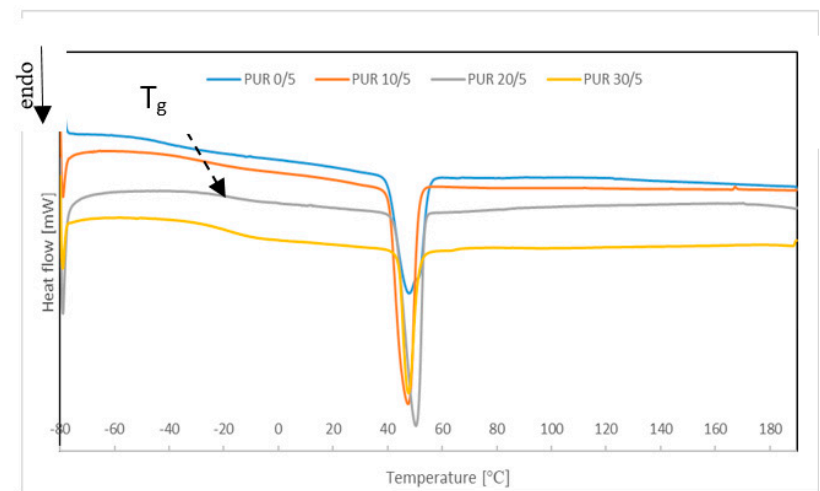

(a)

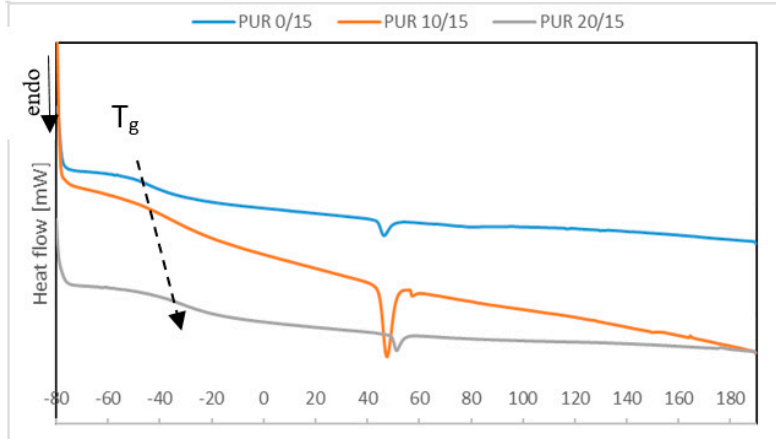

Temperature $\left[{ }^{\circ} \mathrm{C}\right]$

(b)

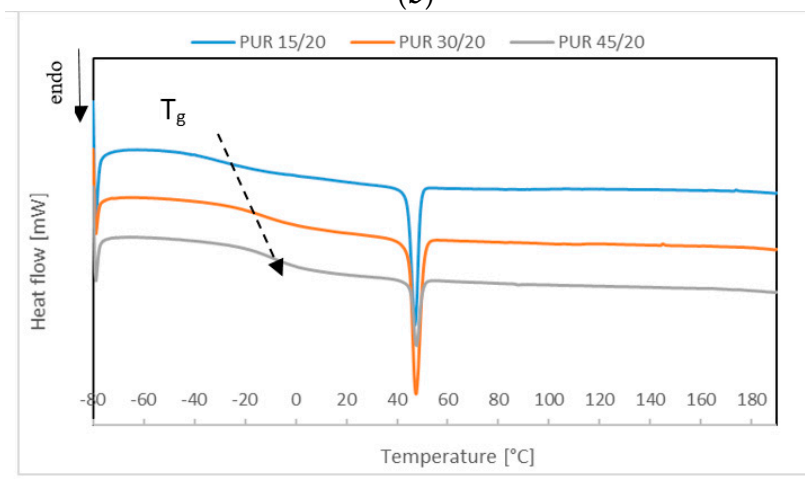

(c)

Figure 3. DSC thermograms of the first heating scan of (a) PUR $x / 5$; (b) PUR $x / 15$; and (c) PUR $x / 20$. 


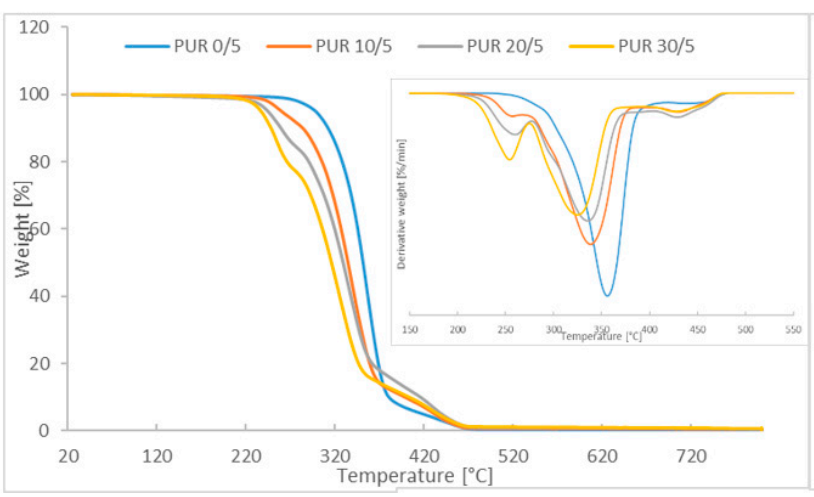

(a)

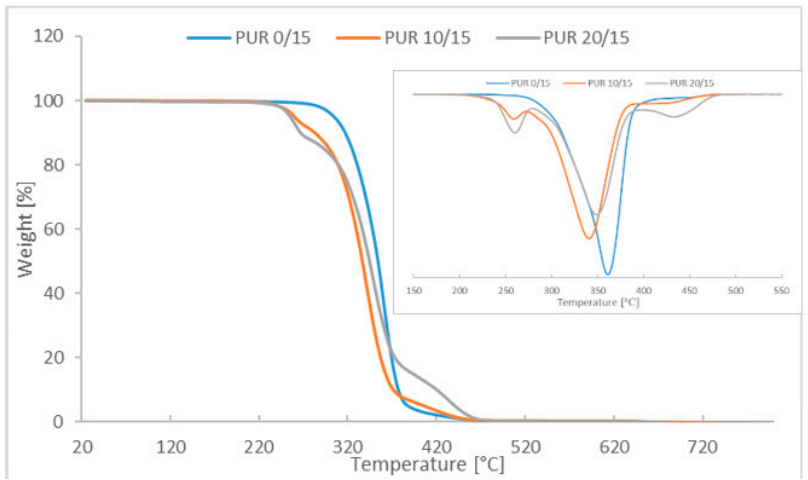

(b)

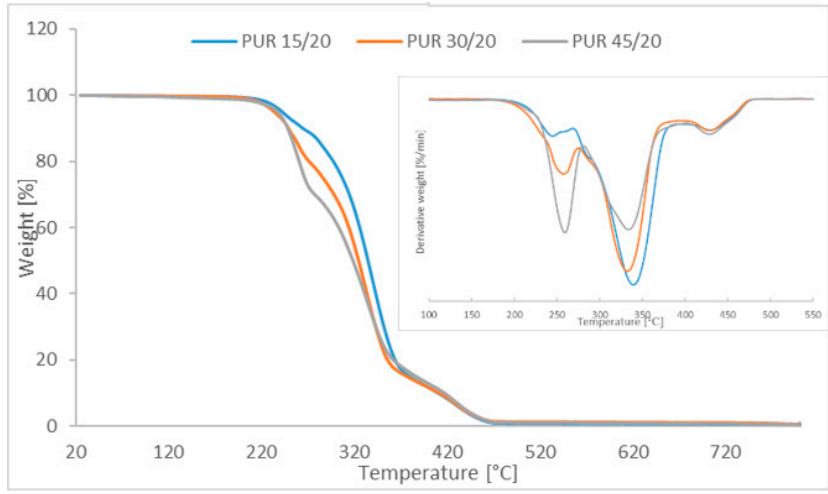

(c)

Figure 4. TGA and DTG curves of (a) PUR x/5, (b) PUR x/15; and (c) PUR x/20.

On the surface of the samples with the highest enthalpy of melting of soft segments (Table 3), the lamellas (marked with white arrows in Figure 5) that could organize into spherules were visible. The spherules and a clear boundary between them on AFM images of PUR 10/5 and PUR 20/5 were marked with red arrows in Figure 5. The width of these lamellas was within 10-40 nm. Cross-sectional images indicated that lamellas occurred also throughout the entire sample volume (Figure S2, Supplementary Materials).

The PUR 0/5 surface was irregular, with inclusions of $700 \mathrm{~nm} \times 500 \mathrm{~nm}$ (large inclusions), $140 \mathrm{~nm} \times 220 \mathrm{~nm}$ (medium inclusions) and $60 \mathrm{~nm} \times 70 \mathrm{~nm}-90 \mathrm{~nm} \times 130 \mathrm{~nm}$ (fine inclusions) (Figure 5). On the surface of PURs with the larger amount of PCL $\mathrm{L}_{t}$ in soft segments, a few inclusions and the small number of lamellase (marked with white arrows) of the width of 10-20 nm were observed (e.g., PUR 0/15 and PUR 30/20). However, they were not arranged into any crystalline forms, as it was confirmed by the DSC investigation (low melting enthalpy was observed for these polymers) (Table 3). 
Table 3. Results of the DSC and TGA analysis of polyurethanes.

\begin{tabular}{lcccccccc}
\hline $\begin{array}{l}\text { PUR } \\
\left(\mathbf{P H B} / \mathbf{P C L}_{\mathbf{t}}\right)\end{array}$ & $\begin{array}{c}\boldsymbol{T}_{\mathbf{g}} \mathbf{I} \\
\left({ }^{\circ} \mathbf{C}\right)\end{array}$ & $\begin{array}{c}\boldsymbol{T}_{\mathbf{g}} \mathbf{I I} \\
\left({ }^{\circ} \mathbf{C}\right)\end{array}$ & $\begin{array}{c}\boldsymbol{T}_{\mathbf{m}} \\
\left({ }^{\circ} \mathbf{C}\right)\end{array}$ & $\begin{array}{c}\Delta \mathbf{H} \\
{[\mathbf{J} / \mathbf{g}]}\end{array}$ & $\begin{array}{c}\boldsymbol{T}_{\mathbf{i}} \\
\left({ }^{\circ} \mathbf{C}\right)\end{array}$ & $\begin{array}{c}\boldsymbol{T}_{\mathbf{5} \%} \\
\left({ }^{\circ} \mathbf{C}\right)\end{array}$ & $\begin{array}{c}\boldsymbol{T}_{\mathbf{1 0}} \\
\left({ }^{\circ} \mathbf{C}\right)\end{array}$ & $\begin{array}{c}\boldsymbol{T}_{\mathbf{f}} \\
\left({ }^{\circ} \mathbf{C}\right)\end{array}$ \\
\hline PUR 0/5 & -43.1 & -46.6 & 47.8 & 20.9 & 267.4 & 287.3 & 295.3 & 467.6 \\
\hline PUR 10/5 & -24.5 & -42.2 & 47.5 & 27.4 & 243.5 & 265.9 & 285.8 & 453.3 \\
\hline PUR 20/5 & -18.0 & -36.4 & 50.4 & 25.8 & 231.3 & 249.5 & 264.2 & 458.1 \\
\hline PUR 30/5 & -19.7 & -28.9 & 47.7 & 12.8 & 223.3 & 240.7 & 250.9 & 457.4 \\
\hline PUR 10/15 & -45.3 & -41.8 & 46.2 & 0.9 & 278.0 & 303.2 & 316.1 & 450.0 \\
\hline PUR 20/15 & -33.0 & -28.3 & 51.1 & 0.9 & 238.3 & 253.1 & 266.4 & 460.0 \\
\hline PUR 15/20 & -39.4 & -42.5 & 47.1 & 7.7 & 227.2 & 244.8 & 268.4 & 456.7 \\
\hline PUR 30/20 & -11.5 & -17.7 & 47.5 & 10.1 & 221.9 & 237.9 & 251.7 & 458.1 \\
\hline PUR 45/20 & -8.9 & -7.2 & 47.7 & 3.6 & 223.2 & 242.0 & 248.7 & 457.5 \\
\hline
\end{tabular}

$T_{\mathrm{g}}$ I_glass transition temperature of soft segments from DSC thermograms of 1st heating scan; $T_{\mathrm{g}}$ II_glass transition temperature of soft segments from DSC thermograms of 2nd heating scan; $T_{m}$-melting temperature of soft segments from DSC thermograms of 1st heating scan; $\Delta \mathrm{H}$-melting enthalpy of soft segments from DSC thermograms of 1st heating scan; $T_{\mathrm{i}}$-initial decomposition temperature of samples (1\% degradation of samples); $T_{5 \%}$-temperature of $5 \%$ degradation of samples; $T_{10}$-temperature of $10 \%$ degradation of samples; $T_{\mathrm{f}}$-final decomposition temperature of samples (corresponds to 1\% residual dry mass of sample after thermal degradation).

As it is well-known, darker zones in the AFM phase images correspond to the amorphous phase of PURs, while brighter zones correspond to the crystalline phase of these PURs. Taking this into consideration, the AFM results can be correlated with the DSC results [21], the AFM phase images of polyurethanes indicate that PUR $\mathrm{x} / 15$ samples were the least crystalline material.

Introducing R,S-PHB into the structure of PURs with low branching points (PUR $x / 5$ ) significantly reduced root mean square roughness $\left(R_{\mathrm{q}}\right)$ from $85 \mathrm{~nm}$ for PUR $0 / 5$ to even $14 \mathrm{~nm}$ in the case of PUR 30/5 (Table S4, Supplementary Materials). The effect of R,S-PHB on roughness was much smaller in the case of PURs with more branching nodes.

Images of the surface in the microscopic scale (under the optical microscope) were in good agreement with AFM observations. On the surface of PUR $x / 5$ with tendency to crystallisation, the characteristic circular objects were visible. Surface topography of other polyurethanes was smooth with no pores or protrusions, but with fine, heterogeneous inclusions.

The contact angle of the synthetized polyurethanes was high, near hydrophobic materials. However, as depicted in Figure 6 the contact angle observed after 3 min from immersing of a water drop on the polymer surface was significantly reduced. This phenomenon was observed also for polyurethanes without R,S-PHB, but changes in these case were lower. This indicated affinity of these polymers to water.

Samples with higher roughness should supposedly have a lower contact angle [22]. However, the obtained results did not confirm this. Also, the expected increase in water contact, due to the increased cross-links, was not found [23]. An increase in the amount of PCL $\mathrm{L}_{\mathrm{t}}$ in the structure of soft segments (at the same time reduction in $\mathrm{M}_{\mathrm{c}}$ ) from $5 \mathrm{wt} \%$ to $15 \mathrm{wt} \%$ increased the contact angle, whereas a further increase in the amount of triol reduced it (Figure 6 and Table S4). The highest contact angle was observed for the second series of PUR with $15 \mathrm{wt} \% \mathrm{PCL}_{\mathrm{t}}$. It was clearly seen that polyurethanes without R,S-PHB were characterized by the highest contact angle.

It is believed that after film formation, on the sample contact surface with air, were mainly PCL chains because of their hydrophobicity. However, as it was said before, after $3 \mathrm{~min}$ from the placement of the water drop, the angle decreased, which indicated an increase in the affinity of polyurethanes to water. These changes were higher for PURs with R,S-PHB. This was due to the higher hydrophilicity of the R,S-PHB chains than PCL, as there was more carbonyl groups capable to forming hydrogen 
bonds with water in R,S-PHB. Thus, hydrophilic R,S-PHB chains migrated to the sample surface under the influence of water droplets.

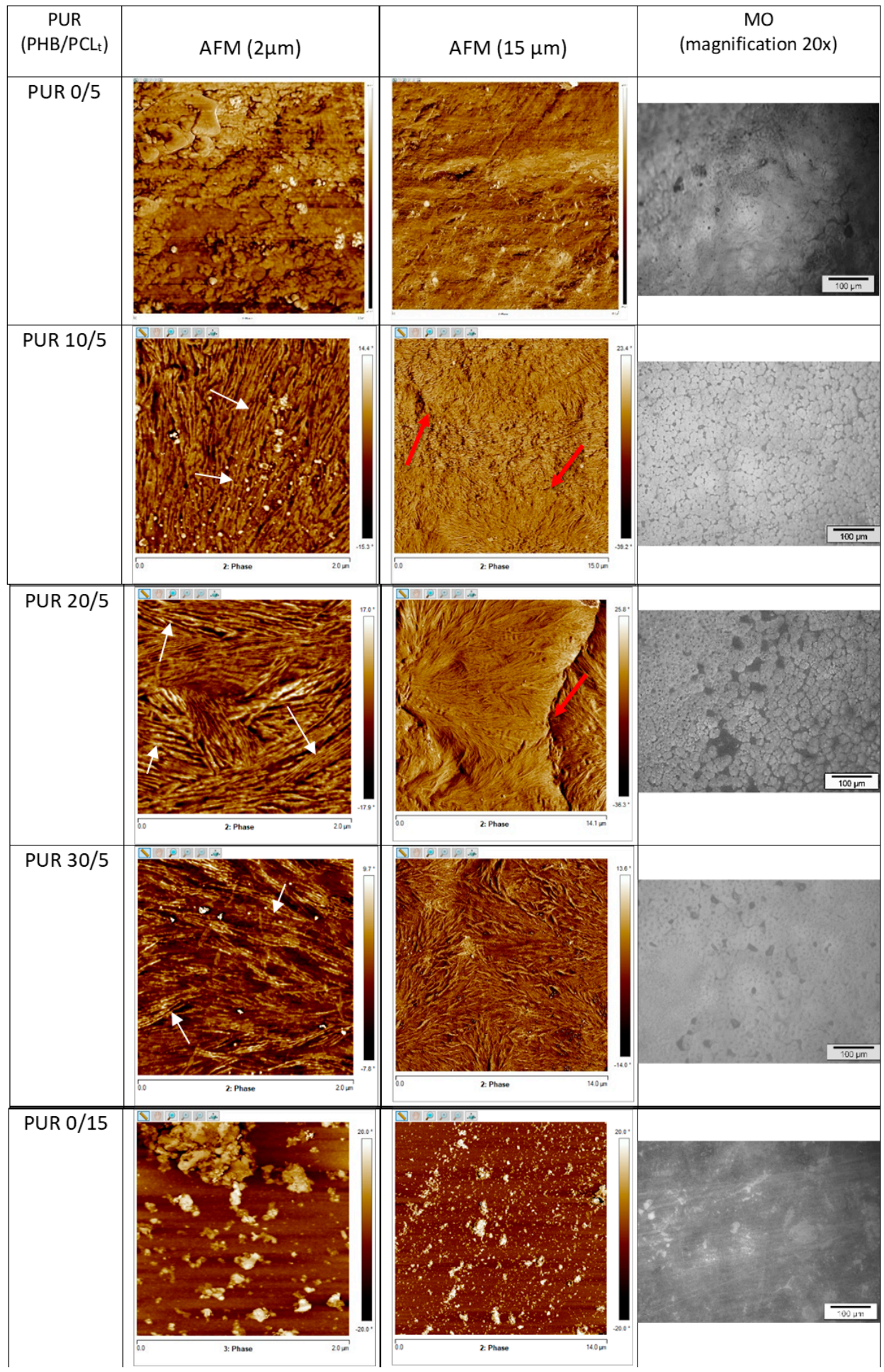

Figure 5. Cont. 


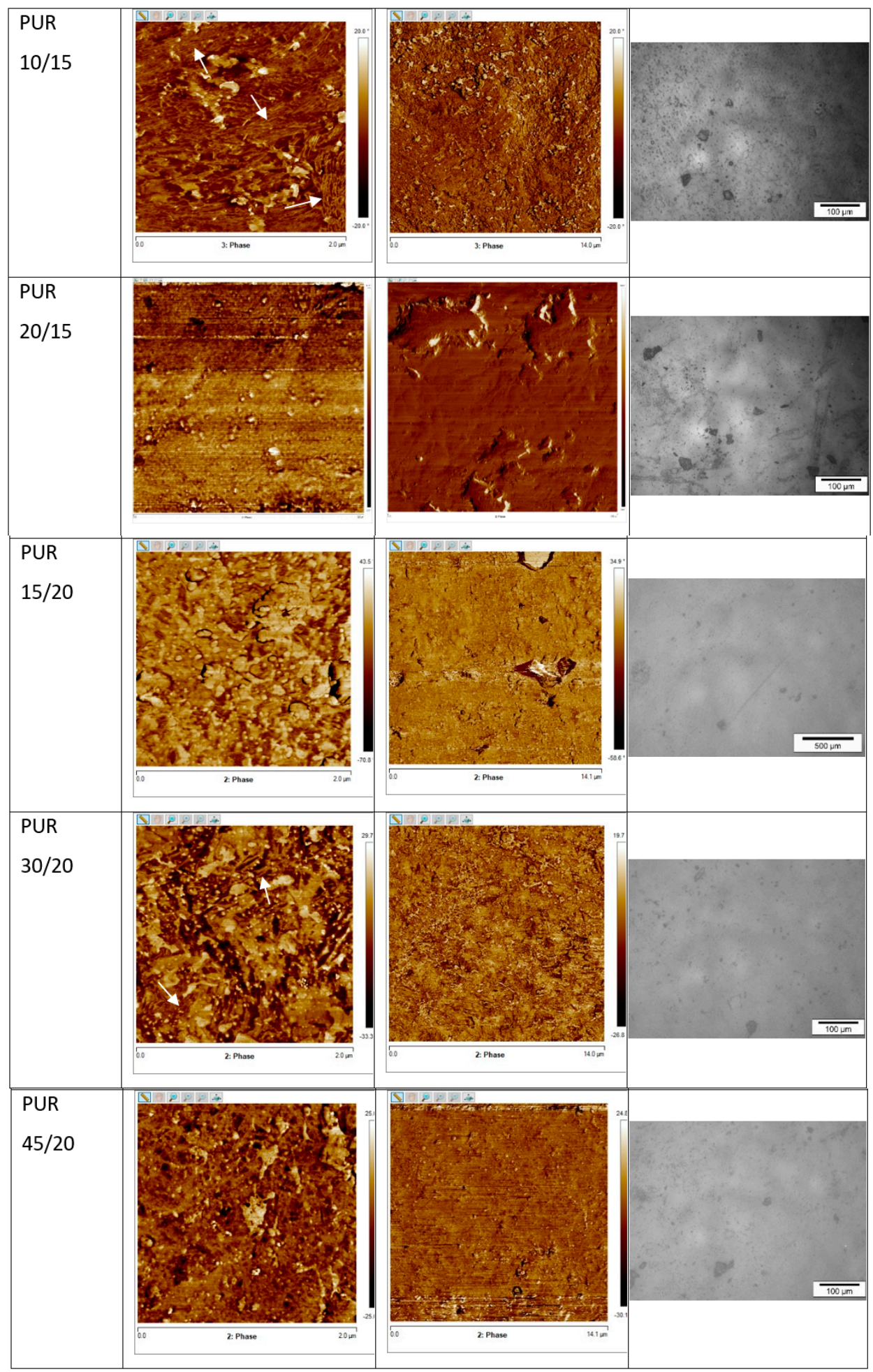

Figure 5. AFM phase and MO images of surface of branched polyurethanes (images for PUR 10/5 and PUR 20/5 were presented in the paper [9]).

In case of almost linear PUR $x / 5$, the ordering of chains and crystallinity was the highest, and the free migration of PCL chains to the surface was limited. The presence of R,S-PHB on PURs surface was observed by ATR-FTIR analysis. In contrast, the interaction in PUR $x / 15$ between the chains was much smaller (which was confirmed by the DSC results) due to greater number of branches so the hydrophobic PCL chains could easily move to the surface of the sample, and the contact angle increased. 
However, with the highest quantity of $\mathrm{PCL}_{\mathrm{t}}$, polyurethanes were cross-linked, which resulted in reduced polycaprolactone chains mobility during the sample formation, hence the reduction of the contact angle to values similar to PUR $x / 5$.

The water affinity of the obtained polyurethanes, observed during the contact angle measurements, was confirmed by a high water uptake. Water absorption percentage visibly increased with an increase in immersion time for all samples, and despite of 21 days of incubation, some samples did not obtain the equilibrium swelling.

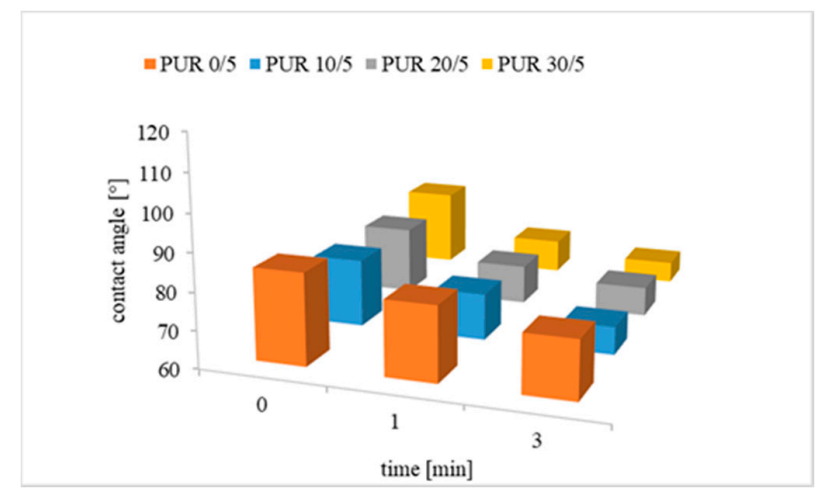

(a)

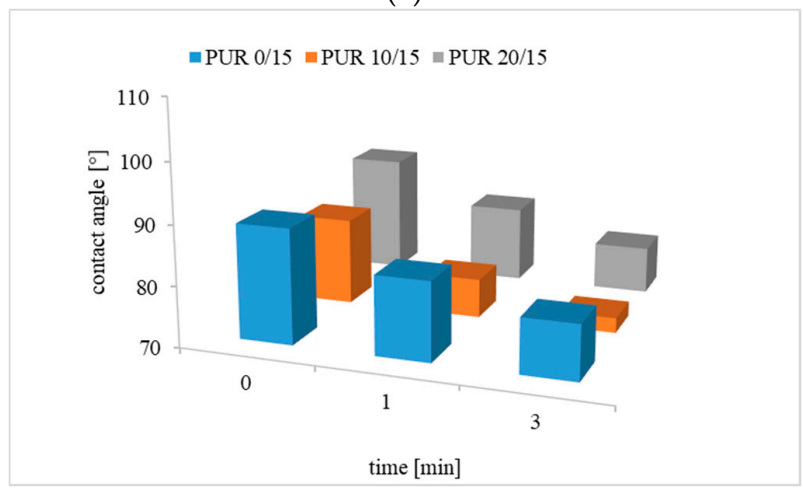

(b)

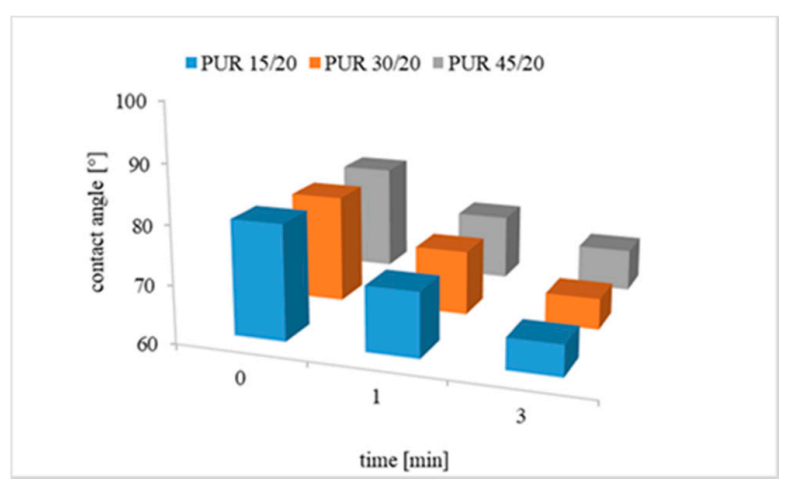

(c)

Figure 6. Contact angle of (a) PUR x/5; (b) PUR x/15; and (c) PUR x/20 0, 1 and 3 min after immersion of a water drop on the sample surface.

The samples of polyurethanes without R,S-PHB increased their weight only by $1.6 \%$ after the first day of incubation in water, and this value did not change during investigations (Figure 7). Undoubtedly, addition of R,S-PHB into the structure of soft segments caused a significant increase in water sorption. The same tendency was observed by Wang and others [24]. Moreover, the greater the amount of $\mathrm{R}, \mathrm{S}-\mathrm{PHB}$ in the polyurethane network, the greater water sorption. The highest amount of water was absorbed for PUR 45/20 polymer with the soft segments built in almost half with R,S-PHB. 


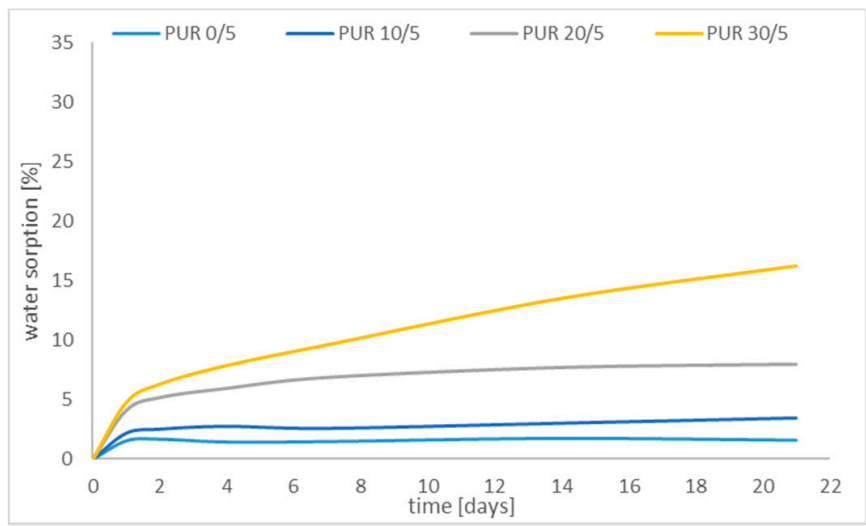

(a)

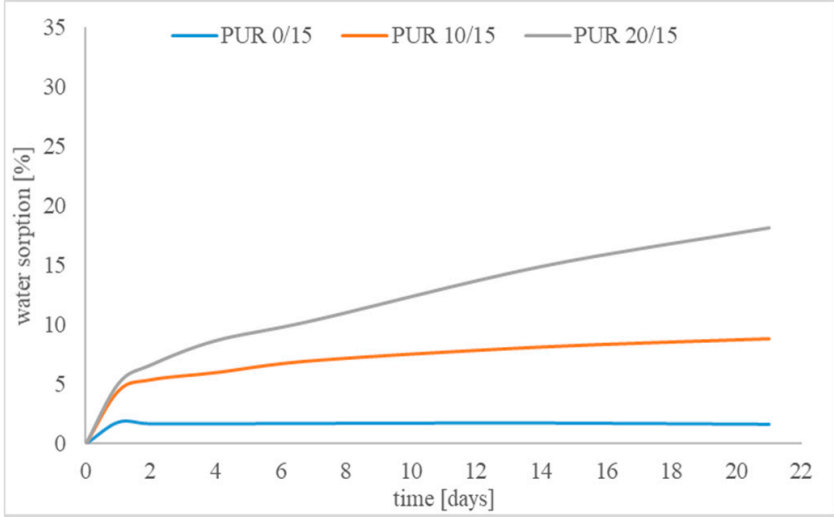

(b)

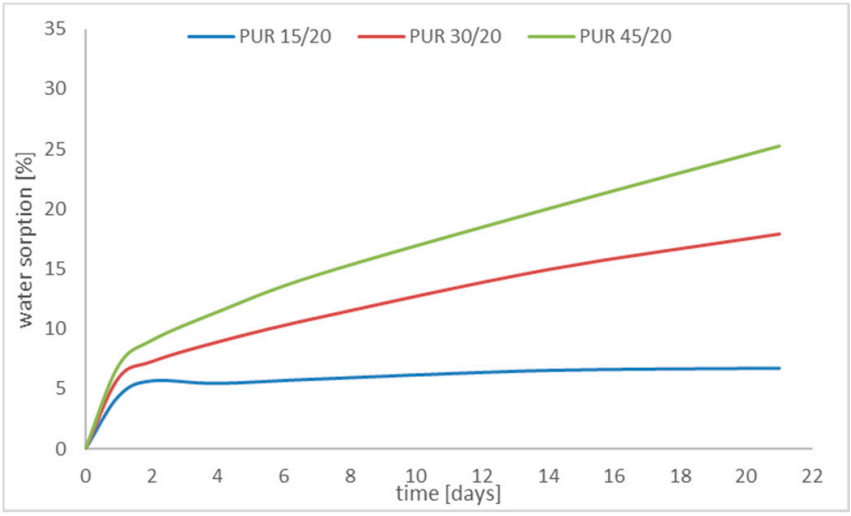

(c)

Figure 7. Water sorption of (a) PUR x/5; (b) PUR x/15; and (c) PUR x/20.

Samples with $5 \mathrm{wt} \%$ of $\mathrm{PCL}_{\mathrm{t}}$ in soft segments absorbed the lowest amount of water. The highest $M_{\mathrm{c}}$ of chains between branch points was connected with the highest possibility of interaction (such as hydrogen bonds) between long aliphatic polyurethane chains and water molecules hardly penetrated inside the bulk sample. As the content of side $\mathrm{CH}_{3}$ groups increased (Table 1), those interactions were inhibited, which facilitated penetration of water into the polyurethane network. Meanwhile, when the amount of $P C L_{t}$ increased, the polymer with large free spaces, limited through cross-linking, was obtained. Relatively long chains between the network nodes (high $M_{\mathrm{c}}$ ) caused that water could penetrate. Hence, an increase in water sorption was observed in the case of PUR x/15. However, when the number of cross-links was too high (as in the case of PUR x/20), water molecules could not penetrate deep into the network.

The relation between tensile strength and the amount of R,S-PHB in the structure of soft segments and values in samples hardness are depicted in Figure 8. 

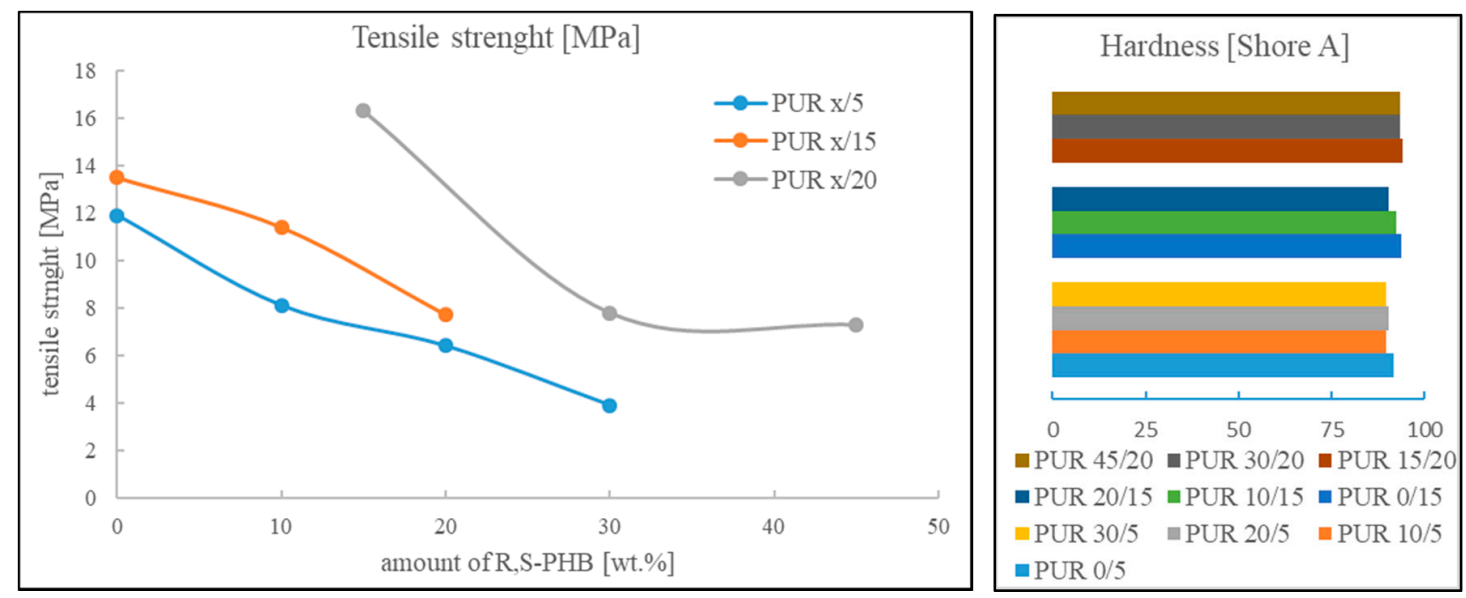

Figure 8. Dependence of tensile strength on the amount of R,S-PHB in the structure of polyurethanes and their hardness.

Tensile strength values were not high, but they were still higher than for example in the case of polyurethane composite with natural PHB used as reinforcement [25]. Two significant parameters affected tensile strength: The number of cross-links (introduced with $\mathrm{PCL}_{\mathrm{t}}$ ) and the amount of R,S-PHB in soft segments. In all PUR series there was a trend of a decrease in tensile strength with an increase of R,S-PHB in the network (Figure 8). It was supposed that the reason was the presence of a secondary group in the R,S-PHB chain, which hindered the reaction with NCO groups; and consequently, the structure was not uniform and statistically repeatable. This caused worse ordering of individual segments, and thus, reduced the interaction between chains and deteriorated mechanical properties. Wang and others found that by introducing a higher amount of natural polyhydroxybutarate diol (also with a secondary hydroxyl group), the tensile strength of polyurethanes proved to be higher [24]. Thus, the amorphous R,S-PHB affect the PURs properties in different way than crystalline R-PHB. We suppose that the crystalline nature of natural PHB could be the reason this increased strength.

The number of branching nodes was another considered factor that affected mechanical strength. Increasing the amount of cross-linking by using more quantity of $\mathrm{PCL}_{t}$ and reducing $\mathrm{M}_{\mathrm{C}}$, between cross-linking nodes, increased tensile strength of polyurethanes, which was expected [26].

The hardness of PURs samples was high and slightly decreased after R,S-PHB adding. At the same time hardness of samples increased after increasing the amount of triol (Figure 8 and Table S5, Supplementary Materials). The increasing of polyurethane hardness with increasing in cross-links number is well known [26]. However, it was expected that differences between hardness of branched PURs and samples with higher amount of PCL $\mathrm{L}_{t}$ would be more significant. Moreover, hardness of the samples with low branching nodes should be lower. On the other hand, the highest PUR $x / 5$ crystallinity was antagonistic to the effect of the highest linearity of these polyurethanes and, consequently, hardness did not degrease as much, as it was expected.

\section{Conclusions}

In this work the results of physic-chemical, structural, thermal and sorptive properties of branched and cross-linked polyurethanes, based on synthetic poly([R,S]-3-hydroxybutyrate), were described. It was proved that the use of such an amorphous, synthetic analogue of natural PHB and manipulation of the amount of triol $\left(\mathrm{PCL}_{\mathrm{t}}\right)$ could provide an opportunity to design the properties of the finished polyurethane. On the whole, introducing R,S-PHB and its further increasing in soft segments of polyurethanes significantly affected their properties: more hydrogen bonds were formed, glass transition temperature of soft segments increased, initial thermal degradation declined, crystallinity was changed, the contact angle decreased, water sorption raised and tensile strength decreased. 
Meanwhile, increasing in the amount of $\mathrm{PCL}_{t}$ in soft segments increased the number of short side chains and branch/cross-links nodes, with reduced $\mathrm{M}_{\mathrm{c}}$ between them. These factors affected the glass transition temperature and melting enthalpy, which increased after adding more than $5 \mathrm{wt} \%$ of triol into soft segments. It also facilitated the water sorption, but only to a certain $\mathrm{PCL}_{t}$ value (PUR x/15), as further increases in its quantity (in the case of PUR $x / 20$ ) caused a significant increase in the number of cross-linking nodes, which made it difficult for water molecules to penetrate. The mechanical properties increased after increased $\mathrm{PCL}_{\mathrm{t}}$.

To sum up, it was found out that by modifying the amount of polycaprolactone triol and poly([R,S]-3-hydroxybutyrate) in soft segment, a polyurethane material with the assumed thermal, sorption and mechanical properties could be obtained. However, linear changes in the properties of polyurethanes with increase $\mathrm{PCL}_{\mathrm{t}}$ could only be predicted to a certain limited value of the amount of triol, because then they were affected by too many cross-links.

Supplementary Materials: The following are available online at http://www.mdpi.com/2073-4360/12/5/1068/s1, Figure S1: ATR-FTIR spectra of PURs, Figure S2: AFM cross-section images of PURs, Table S1: ATR-FTIR bands of polyurethanes in the range of 4000 to $1200 \mathrm{~cm}^{-1}$, Table S2: ATR-FTIR bands of polyurethanes in the range of 1300 to $1000 \mathrm{~cm}^{-1}$, Table S3: Degradation temperature $\left(T_{\text {degr }}\right)$ at three stages of degradation from DTG curves, Table S4: Root mean square roughness $\left(R_{\mathrm{q}}\right)$ and average roughness $\left(\mathrm{R}_{\mathrm{a}}\right)$ of AFM and contact angle of PURs, Table S5: Hardness of the obtained polyurethanes.

Author Contributions: Conceptualization, J.B.; methodology, J.B. and A.T.; validation, J.B. and A.T.; formal analysis, J.B.; investigation, J.B., A.T. and W.S.; resources, J.B., W.S. and A.T.; writing-original draft preparation, J.B.; writing — review and editing, J.B., A.T. and W.S.; visualization, J.B.; supervision, M.R. and M.K.; project administration, J.B.; funding acquisition, J.B. All authors have read and agreed to the published version of the manuscript.

Funding: This research was founded by the National Science Center Miniatura 2 project no. 2018/02/X/ST5/02005 and partially by the UMG research project no. WPiT/2020/PZ/01.

Conflicts of Interest: The authors declare no conflict of interest.

\section{References}

1. Di, Y.; Xia, H.; Jiao, Y.; Zhang, X.; Fang, Q.; Li, F.; Chen, S. Biodegradation of polyhydroxybutyrate by Pseudomonas sp. DSDY0501 and purification and characterization of polyhydroxybutyrate depolymerase. 3 Biotech. 2019, 9, 359. [CrossRef] [PubMed]

2. Dalsasso, R.R.; Pavan, F.A.; Bordignon, S.E.; de Aragão, G.M.F.; Poletto, P. Polyhydroxybutyrate (PHB) production by Cupriavidus necator from sugarcane vinasse and molasses as mixed substrate. Process Biochem. 2019, 85, 12-18. [CrossRef]

3. Haddadi, M.H.; Asadolahi, R.; Negahdari, B. The bioextraction of bioplastics with focus on polyhydroxybutyrate: A review. Int. J. Environ. Sci. Technol. 2019, 16, 3935-3948. [CrossRef]

4. Yeo, J.C.C.; Muiruri, J.K.; Thitsartarn, W.; Li, Z.; Hea, C. Recent advances in the development of biodegradable PHB-based toughening materials: Approaches, advantages and applications. Mater. Sci. Eng. C 2018, 92, 1092-1116. [CrossRef] [PubMed]

5. Domiński, A.; Konieczny, T.; Zięba, M.; Klim, M.; Kurcok, P. Anionic Polymerization of $\beta$-Butyrolactone Initiated with Sodium Phenoxides. The Efect of the Initiator Basicity/Nucleophilicity on the ROP Mechanism. Polymers 2019, 11, 1221. [CrossRef]

6. Arslan, H.; Adamus, G.; Hazer, B.; Kowalczuk, M. Electrospray ionisation tandem mass spectrometry of poly[R,S)-3-hydroxybutanoic acid] telechelics containing primary hydroxyl end groups. Rapid Commun. Mass Spectrom. 1999, 13, 2433-2438. [CrossRef]

7. Brzeska, J.; Elert, A.M.; Morawska, M.; Sikorska, W.; Kowalczuk, M.; Rutkowska, M. Branched Polyurethanes Based on Synthetic Polyhydroxybutyrate with Tunable Structure and Properties. Polymers 2018, $10,826$. [CrossRef]

8. Sienkiewicz, N.; Członka, S.; Kairyte, A.; Vaitkus, S. Curcumin as a natural compound in the synthesis of rigid polyurethane foams with enhanced mechanical, antibacterial and anti-ageing properties. Polym. Test. 2019, 79, 106046. [CrossRef] 
9. Brzeska, J.; Tercjak, A.; Sikorska, W.; Kowalczuk, M.; Rutkowska, M. Morphology and Physicochemical Properties of Branched Polyurethane/Biopolymer Blends. Polymers 2020, 12, 16. [CrossRef]

10. Fridrihsone, A.; Stirna, U.; Lazdina, B.; Misane, M.; Vilsone, D. Characterization of polyurethane networks structure and properties based on rapeseed oil derived polyol. Eur. Polym. J. 2013, 49, 1204-1214. [CrossRef]

11. Petrović, Z.S. Polyurethanes from Vegetable Oils. Polym. Rev. 2008, 48, 109-155. [CrossRef]

12. Mizera, K.; Ryszkowska, J.; Kurańska, M.; Prociak, A. The effect of rapeseed oil-based polyols on the thermal and mechanical properties of ureaurethane elastomers. Polym. Bull. 2019. [CrossRef]

13. Liu, M.; Zhong, J.; Li, Z.; Rong, J.; Yang, K.; Zhou, J.; Shen, L.; Gao, F.; Huang, X.; He, H. A high stiffness and self-healable polyurethane based on disulfide bonds and hydrogen bonding. Eur. Polym. J. 2020, 124, 109475. [CrossRef]

14. Majka, T.M.; Pielichowski, K. Thermal degradation of polymanide/layered silicate nanocomposites. Tech. Trans. 2011, 2-Ch/2011, 133-142. (In Polish)

15. Rybiński, P. Stabilność termiczna i palność elastomerów oraz materiałów elastomerowych. In Zeszyty Naukowe; Wydawnictwo Politechniki Łódzkiej: Łódź, Poland, 2014; p. 1182. (In Polish)

16. Yilgör, I.; Yilgör, E.; Wilkes, G.L. Critical parameters in designing segmented polyurethanes and their effect on morphology and properties: A comprehensive review. Polymer 2015, 58, A1-A36. [CrossRef]

17. Qin, H.; Wang, K. Study on preparation and performance of PEG-based polyurethane foams modified by the chitosan with different molecular weight. Int. J. Biol. Macromol. 2019, 140, 877-885. [CrossRef]

18. Duong, T.H.; Margaillan, A.; Bressy, C. Thermal degradation of hydroxyalkylated poly(dimethylsiloxane)s and poly(dimethylsiloxane)-poly(trialkylsilyl methacrylate) based block copolymers synthesized by RAFT polymerization. Polym. Degrad. Stabil. 2019, 164, 136-144. [CrossRef]

19. Ferriol, M.; Gentilhomme, A.; Cochez, M.; Oget, N.; Mieloszynski, J.L. Thermal degradation of poly(methyl methacrylate) (PMMA): Modelling of DTG and TG curves. Polym. Degrad. Stabil. 2003, 79, 271-281. [CrossRef]

20. Pagacz, J.; Hebda, E.; Janowski, B.; Sternik, D.; Jancia, M.; Pielichowski, K. Thermal decomposition studies on polyurethane elastomers reinforced with polyhedral silsesquioxanes by evolved gas analysis. Polym. Degrad. Stabil. 2018, 149, 129-142. [CrossRef]

21. Schön, P.; Bagdi, K.; Molnár, K.; Markus, P.; Pukánszky, B.; Vancso, G.J. Quantitative mapping of elastic moduli at the nanoscale in phase separated polyurethanes by AFM. Europ. Polym. J. 2011, 47, 692-698.

22. Liang, W.; Xu, Y.; Li, X.; Wang, X.-X.; Zhang, H.-D.; Yu, M.; Ramakrishna, S.; Long, Y.-Z. Transparent Polyurethane Nanofiber Air Filter for High-Efficiency PM2.5 Capture. Nanoscale Res. Lett. 2019, $14,361$. [CrossRef] [PubMed]

23. Acik, G.; Karabulut, H.R.F.; Altinkok, C.; Karatavuk, A.O. Synthesis and characterization of biodegradable polyurethanes made from cholic acid and L-lysine diisocyanate ethyl ester. Polym. Degrad. Stabil. 2019, 165, 43-48. [CrossRef]

24. Wang, C.; Xie, J.; Xiao, X.; Chen, S.; Wang, Y. Development of Nontoxic Biodegradable Polyurethanes Based on Polyhydroxyalkanoate and L-lysine Diisocyanate with Improved Mechanical Properties as New Elastomers Scaffolds. Polymers 2019, 11, 1927. [CrossRef] [PubMed]

25. Kupka, V.; Benesova, P.; Obruca, S.; Brtnikova, J.; Marova, I.; Jancar, J.; Vojtova, L. Biodegradation of polyurethane-polyhydroxybutyrate elastomeric composite investigated from morphological and structural viewpoint. J. Appl. Polym. Sci. 2019. [CrossRef]

26. HyeLin, K.; YoungHee, L.; JungSoo, K.; ChaCheol, P.; Hyun, P.; HoHwan, C.; HanDo, K. Preparation and properties of crosslinkable waterborne polyurethane and polyurethane-acrylic hybrid emulsions and their crosslinked polymers. J. Polym. Res. 2016, 23, 240. [CrossRef]

(C) 2020 by the authors. Licensee MDPI, Basel, Switzerland. This article is an open access article distributed under the terms and conditions of the Creative Commons Attribution (CC BY) license (http://creativecommons.org/licenses/by/4.0/). 